(C) 1996 IEEE. Personal use of this material is permitted. However, permission to reprint/republish this material

for advertising or promotional purposes or for creating new collective works for resale or redistribution to servers

or lists, or to reuse any copyrighted component of this work in other works must be obtained from the IEEE.

\title{
RELIABILITY OF THE LEP VACUUM SYSTEM: EXPERIENCE AND ANALYSIS
}

\section{P.M. Strubin, J.-P. Bojon, CERN, CH-1211 Geneva 23, Switzerland}

\section{INTRODUCTION}

The LEP vacuum system extends over $26 \mathrm{~km}$ and consists of more than 6000 chambers, bellows, valves and special equipment. Adding the various pumps and gauges, a total of 13000 gaskets is required to mount all equipment. Hence, it is the largest vacuum system ever built for an accelerator.

The major part of the vacuum system, mainly in the bending arcs, is made of extruded aluminium chambers, connected together by means of stainless steel bellows to cope with thermal expansion and adjustment of mounting tolerances. Aluminium gaskets are used on so called LEP type flanges. This part of the vacuum system is pumped by Non Evaporable Getter pumps [1] (NEG), with additional sputter ion pumps; it is limited to a bake out temperature of $150^{\circ} \mathrm{C}$. The remaining part, refered to as the straight sections, is made out of stainless steel chambers and bellows, connected using copper gaskets; it is hence baked to $300^{\circ} \mathrm{C}$. This part of the vacuum system is pumped by sputter ion pumps and titanium sublimation pumps. The special equipment, like accelerating cavities or electrostatic separators, is also installed in the straight sections. The vacuum system is split into manageable sectors by means of sector valves. The length of these sectors can vary between a few metres and 474 metres. A detailed description of the vacuum system of LEP can be found in $[2,3]$.

The procedures for all interventions, in particular leak detection, bake-out and commissioning, are of utmost importance for the global reliability of the vacuum system and will be detailed in this paper.

As important for the global reliability are the power supplies and the remote control of the various equipment of the vacuum system. A careful initial design [4] and preventive maintenance are the keys for it and will be described in this paper too.

\section{STATISTICS}

LEP operation started in July 1989. At that time, a small number of leaks had been sealed with varnish after the initial bake-out and commissioning, as they were considered small enough so as not to justify a repair. Table 1 summarises these leaks and represents the actual starting point for our statistics.

The choice to varnish these leaks was fully justified, as none of them opened up until now or before a proper repair could be scheduled. A small number of additional leaks have nevertheless developed over the years. Table 2 summarises them.
Table 1: varnish sealed leaks at startup in 1989

\begin{tabular}{|l|c|c|l|}
\hline Components & $\begin{array}{c}\text { Quantity } \\
\text { installed }\end{array}$ & $\begin{array}{c}\text { Number of } \\
\text { leaks sealed }\end{array}$ & $\%$ \\
\hline NEG feedthrough & 3768 & 7 & 0.2 \\
\hline Ion pump feedtrough & 1346 & 3 & 0.2 \\
\hline PU electrode & 1712 & 6 & 0.4 \\
\hline Al gasket, Ø 225 & 5374 & 2 & 0.04 \\
\hline Al gasket, Ø 113.5 & 7616 & 13 & 0.2 \\
\hline Bellows & 2649 & 5 & 0.2 \\
\hline Weld on Al chamber & 2588 & 1 & 0.04 \\
\hline
\end{tabular}

Table 2: leaks that have developed since 1989

\begin{tabular}{|c|c|c|c|c|}
\hline Year & Date & Sector & $\begin{array}{c}\text { Leak } \\
\text { rate } \\
\text { Torr } 1 / \mathrm{s}\end{array}$ & Comments \\
\hline \multirow[t]{2}{*}{1989} & $7 / 8$ & 361 & $1 * 10^{-5}$ & $\begin{array}{l}\text { Corrosion on a pump feed- } \\
\text { through, LEP not delayed }\end{array}$ \\
\hline & $21 / 9$ & 370 & $1 * 10^{-4}$ & $\begin{array}{l}\text { Corrosion on a pump feed- } \\
\text { through, LEP not delayed }\end{array}$ \\
\hline 1990 & $4 / 7$ & 259 & 10 & $\begin{array}{l}\text { RF window broken at the } \\
\text { end of a technical stop, } \\
\text { LEP not delayed }\end{array}$ \\
\hline \multirow[t]{3}{*}{1991} & $15 / 5$ & 240 & $5 * 10^{-7}$ & $\begin{array}{l}\text { Porosity on an RF cavity } \\
\text { field probe ceramic, LEP } \\
\text { not delayed }\end{array}$ \\
\hline & $21 / 5$ & 170 & $1 * 10^{-4}$ & $\begin{array}{l}\text { Leak on a weld of an } \\
\text { aluminium chamber, start- } \\
\text { up delayed by } 2 \text { days }\end{array}$ \\
\hline & $4 / 10$ & 850 & $1 * 10^{-5}$ & $\begin{array}{l}\text { Leak on the experimental } \\
\text { chamber for Delphi, LEP } \\
\text { stopped for } 10 \text { days }\end{array}$ \\
\hline 1992 & $29 / 3$ & 661 & 1 & $\begin{array}{l}\text { Large leak on an RF } \\
\text { window, start-up delayed } \\
\text { by } 2 \text { days }\end{array}$ \\
\hline 1993 & $14 / 7$ & 241 & 10 & $\begin{array}{l}\text { RF window broken at the } \\
\text { end of a technical stop, } \\
\text { LEP not delayed }\end{array}$ \\
\hline \multirow[t]{3}{*}{1994} & $4 / 5$ & 258 & $1 * 10^{-7}$ & $\begin{array}{l}\text { Leak on a bellows, LEP } \\
\text { not delayed }\end{array}$ \\
\hline & $8 / 6$ & 242 & $1 * 10^{-7}$ & $\begin{array}{l}\text { Leak on a beam } \\
\text { observation electrode, } \\
\text { LEP not delayed }\end{array}$ \\
\hline & $31 / 8$ & 660 & $1 * 10^{-7}$ & $\begin{array}{l}\text { Porosity on an RF cavity } \\
\text { field probe ceramic, LEP } \\
\text { not delayed }\end{array}$ \\
\hline
\end{tabular}

It is important to point out that LEP was only delayed twice, and stopped once, due to vacuum over more than 5 years of operation. This very high reliability could only be achieved by the strict application of precise procedures during every intervention. These procedures will be detailed below. 


\section{LEAK DETECTION}

Leak detection can be done at two different periods: when an intervention on the vacuum system is scheduled or during short interruptions of operation.

In the first case, residual gas analysers are used in place of the more common helium leak detector. This allows for a tenfold increase in the sensitivity and, hence, again in the smallest detectable leaks. Leaks in the $10^{-10}$ Torr $1 / \mathrm{s}$ are routinely found with this technique.

During short interruptions of operation, the sensitivity is reduced to $10^{-6}$ Torr $1 / \mathrm{s}$ where the sputter ion pumps are used to measure the pressures, $10^{-7}$ Torr $1 / \mathrm{s}$ being possible where Bayard-Alpert gauges are installed.

\section{A: Detection during interventions}

\section{Detection before opening a vacuum sector}

A global leak detection using residual gas analysers is done on every vacuum sector which has to be opened for modifications or repairs. Every leak is registered and will be repaired while the sector is at atmospheric pressure. Previously varnish sealed leaks will also be repaired. This is required because the varnish used, although very reliable at room temperature and in presence of radiation, is not intended to be baked.

2 Detection before bake-out

A second global leak detection using residual gas analysers is done after a sector has been pumped down and is ready for bake-out. If at this stage, leaks are found, they will be repaired, not varnish sealed.

3 Detection after bake-out and commissioning

A final global leak detection using residual gas analysers is made after the bake-out and conditioning procedures, at room temperature. If a leak is found at this stage it will be varnish sealed provided it is smaller than $10^{-4}$ Torr 1/s in order to avoid an additional bake-out. In case of larger leaks, a proper repair will be done, implying the complete repetition of the procedure: venting, repair, pump down, bake-out and commissioning.

\section{B: Detection during short interruptions of operation}

If a leak is detected either by the sputter ion pumps or the ionisation gauges, a leak detection using these elements is made. The leak is then varnish sealed and carefully registered, to be repaired during the next intervention in the sector.

\section{BAKE-OUT AND COMMISSIONING}

A complete procedure involves a 24 hour bake-out and what is referred to as commissioning: flashing of the sputter ion pumps, degassing of the ion gauges and sublimation pumps and activation of the NEG pump. Figure 1 illustrates a typical bake-out cycle with NEG.

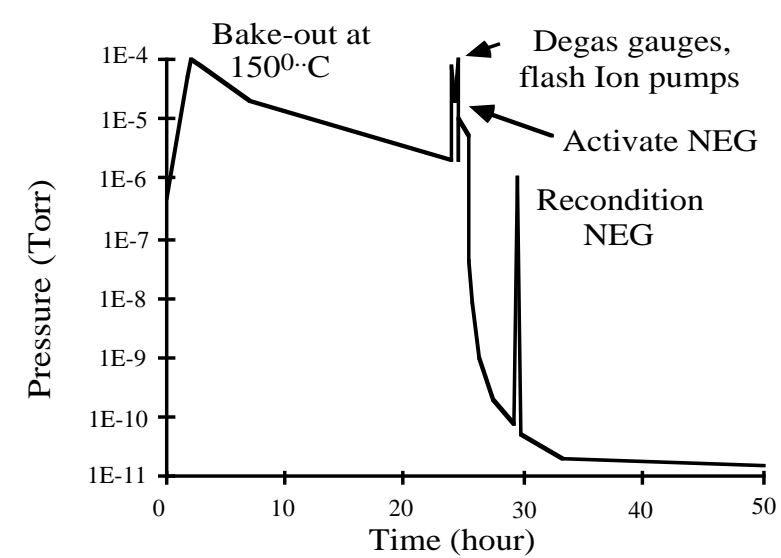

Figure 1: Typical bake-out cycle with NEG

\section{A: Bake-out}

Optimised bake-out procedures are very important for the overall reliability of the vacuum system. A precise temperature control, including control of gradients, is necessary. Figure 2 shows the typical temperatures recorded at various points of an aluminium vacuum chamber and an adjacent stainless steel bellows. The chamber is heated by circulating pressurised hot water in its cooling channels. No additionnal heating is provided for the bellows and the flanges, in order to simplify the bake-out equipment. It can be seen, that although the main part of the chamber is at $150^{\circ} \mathrm{C}$, the flanges and the bellows are at lower temperature This reduced temperature has no influence, however, on the end pressure but it increases the reliability by reducing the risk of a leak on the gasket.

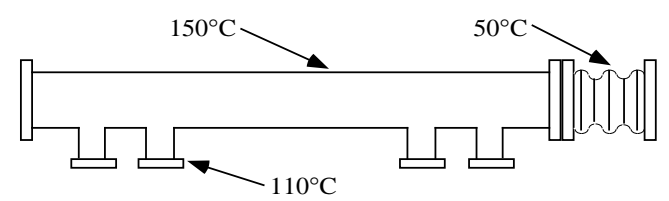

Figure 2: temperature distribution on $\mathrm{Al}$ chambers

Special care is taken for the larger vacuum vessels, such as the electrostatic separators. The temperature gradients are limited to $20^{\circ} \mathrm{C}$ per hour, in order to avoid tempearature differences on the large flanges.

Another delicate component is the sector valve where leaks have developed across the seal when there was an excessive temperature gradient on the body of the valve.

\section{$B$ : activation of the NEG pump}

The activation of the NEG pump is one of the most critical operation during the commissioning. The feedthroughs are at their limit of current handling and their temperature increases to $200^{\circ} \mathrm{C}$ when $90 \mathrm{~A}$ are fed into the NEG ribbon. Before every activation, the current leads are tested for correct tightness. A loose connection would inevitably provoke overheating of the feedthrough and could produce a leak. This would destroy the NEG pump which will burn with the oxygen entering the vacuum chamber. Residual gas analysers, scanning around mass 40 (Ar, which is not 
pumped by the NEG), are used as an interlock to the NEG power supply

\section{PRE-TESTING OF THE EQUIPMENT IN THE LABORATORY}

Every single component of the vacuum system is completely tested in the laboratory prior to installation in the LEP accelerator. This means a full bake-out and the measurement of the ultimate pressure and gas composition. By doing so, not only can we detect manufacturing defects, like faulty welds, but we also make sure that the equipment is really clean. As an example, if a pick-up electrode with traces of oil was mounted in a long sector, up to 474 metres of vacuum system could be irremediably polluted and would have to be completely taken apart to be cleaned. Therefore, the testing of the equipment in the laboratory is also considered as a preventive maintenance activity.

\section{PREVENTIVE MAINTENANCE OPERATIONS}

\section{A: Sputter ion pumps}

The feedthroughs of the sputter ion pumps are heated with a low power heating collar in order to keep them free from moisture. At regular intervals the feedthroughs are visually inspected, but so far traces of corrosion have only been observed on three occasions, with the notable addition of two pumps on to which water had dropped. There is a significant accumulation of dust on them, however, and it will soon be necessary to clean them systematically in order to avoid leakage currents.

Global data logging and retrival programs play an important role for early detection of either pressure rises indicating leaks, or deterioration of the quality of the feedthroughs.

\section{B: Power supplies for the Sputter Ion Pumps}

Because up to six pumps are powered from one supply [4] (to save in cabling costs), the reliability of these power supplies is vital. Furthermore, they are used as interlock source for the sector valves and all special equipment, such as accelerating cavities and electrostatic seperators. The power supplies generate $5.6 \mathrm{kV}$ and hence attract a lot of dust. They are cleaned every second year in order to prevent leakage currents around the high voltage transformer and leads. This proves to be sufficient, as there was no failure due to a faulty high voltage generator. The next critical elements are the high voltage connectors of the cables. There have been a few failures on the tunnel side, most likely due to humidity. However, because individual pumps are decoupled from each other by a high resistance cable, a single failure does not affect the average pumping speed to much. There is a problem for the individual current measurement devices, however, when such a failure occurs.

\section{C: Interlock relays}

A potential problem for reliability are relays in the various interlock chains. Some critical systems, like the accelerating cavities, require that all 256 sputter ion pumps give a good interlock to allow for operation. Because of the good overall reliability of the vacuum system and of the power supplies, these relays are rarely actuated and their contacts degrade with time. Most modern relays have so called selfcleaning contacts, but they require to be actuated. Therefore, all interlock relays are systematically operated three of four times a year, to insure the self-cleaning process By doing so, we can ensure correct operation of the accelerator, leading to an average of two to three short interruptions (less than an hour) per year.

\section{D: Sector valves}

The sector valves are routinely closed during access to the LEP tunnel ring, for security reasons. The most frequent reasons due to vacuum for a delay in startup after an access is that some valve does not operate properly, in particular does not reach its completely opend state. Unfortunately, there is no efficient way to improve this situation. Preventive maintenance is limited to a careful adjustement of the position switches whenever a problem is suspected.

\section{CONCLUSIONS}

By carefully testing all vacuum components in the laboratory prior to installation in the LEP accelerator, we detect and eliminate manufacturing problems and, most important, garantee that the equipment is absolutely clean for an ultra-high vacuum operation.

Performing systematic leak detection with residual gas analysers for maximum sensitivity, allows us to repair all leaks, even very small ones, before the bake-out and commissioning. As important is a systematic record of all known leaks for future repairs.

Several preventive actions, like testing of NEG and pump feedthroughs, are also considered to improve the overall reliability of the LEP vacuum system.

Similarly, preventive maintenance of high voltage supplies and some special actions for interlock relays provides for a reliable operation of the vacuum controls.

All added together and, last but not least, thanks to the very high skill of both CERN and industrial support staff, we can insure a smooth running of the LEP vacuum system.

\section{REFERENCES}

[1] C. Benvenuti, CERN-ISR-VA/82-12

[2] LEP Vacuum Group, Proc. IX IVC, V ICSS, Madrid (1983)

[3] H.P. Reinhard et al, Proc XI IVC, VII ICSS, Köln (1989)

[4] P.M. Strubin, Controls for the LEP Vacuum System, J.Vac.Sci.Technol., A 5(4) Jul/Aug 1987 